Drive:

Measurement of a Sleeping Giant

(C) 2018, American Psychological Association. This paper is not the copy of record and may not exactly replicate the final, authoritative version of the article. Please do not copy or cite without authors' permission. The final article will be available, upon publication, via its DOI: $10.1037 / \mathrm{cpb} 0000123$ 


\begin{abstract}
Effective strategies for increasing work motivation will consider person factors and individual differences. This article expands on the theory and construct of drive in the context of the development of a new inventory and concurrent validation of a short form.

The results support the measurement of drive, which, hitherto, had not been explicitly defined and operationalized accordingly. Exploratory Structural Equation Modelling recovered three oblique factors, labelled "passion", "effort" and "ideation". The instrument also evidenced reliability (internal consistency and test-retest), as well as convergent/discriminant, predictive and incremental validity. Consistency between two forms and with previous results strengthens the robustness of findings. Applications of drive theory and assessment in organizational and career contexts are discussed.
\end{abstract}

Keywords: Drive, motivation, high potential, talent, assessment 
Drive:

Measurement of a Sleeping Giant

Along with competence and personality, motivation is critical to performance and of interest to those involved in recruitment (personnel selection) and talent management (coaching, learning and development [L\&D], etc.; e.g., Kanfer, Frese, \& Johnson, 2017). In the age of an employee "disengagement epidemic" (e.g., surveys suggest that less than a third of the workforce is actively engaged; Gallup, 2017), ${ }^{1}$ organizations are left wondering how to get workers motivated and, ultimately, boost productivity. With the limitations of financial incentives widely acknowledged (Pink, 2009; Schwartz, 2015), modern approaches focus on a range of strategies targeting workers' sense of purpose (work meaning), influence (making a difference in the lives of others), identification with company mission and values, independence and autonomy; the significance of non-monetary incentives, such as regular appreciation of work and investment into employee development, is increasingly recognized (Ariely, 2016; Pearson, 2015; Pink, 2009; Schwartz, 2015; Sinek, Mead, \& Docker, 2017; Strack, 2014).

Amidst general principles, effective strategies for maximizing work motivation need to consider person factors and individual differences. Employees differ in what motivates them and in the extent to which they identify with their organization's mission and core values. Disengagement and non-performance become probable when people are placed into unsuitable roles or assigned the wrong tasks. The motivation assessment literature is saturated with attributes describing a person's motivational direction (needs, motives, goals,

${ }^{1}$ Work disengagement has been defined as: "the uncoupling of selves from work roles; in disengagement, people withdraw and defend themselves physically, cognitively, or emotionally during role performances" (Kahn, 1990, p. 694). 
interests, desires and values) that interact with situational factors to explain engagement, performance and success levels (Mayer, Faber, \& Xu, 2007; Sackett, Lievens, Van Iddekinge, \& Kuncel, 2017).

A general motivational dimension less dependent on contextual factors has a marginal presence in the literature. Yet, drive appears to be distinguishable from other motivation constructs and is argued to have a unique impact on engagement, performance and achievement outcomes (Chamorro-Premuzic, Adler, \& Kaiser, 2017; Kaufman \& Duckworth, 2017; Siegling \& Petrides, 2016). For example, two people could have the same aspirations yet differ in their propensity to act upon them and achieve different results. Independently or in conjunction with other constructs, drive holds promise in contexts as varied as management, education, sports and entrepreneurship (start-ups), specifically in two areas: (a) the organizational context, and (b) career guidance (counselling) and development. This article elaborates on the construct of drive and presents the development of a new inventory, Drive, and its short form, Drive Lite.

\section{Drive Theory}

Drive describes a person's general baseline level of motivation, or the average of motivational states across time and situations (Siegling \& Petrides, 2017, 2016); in other words, the propensity for personal investment in the advancement of one's own, or others', condition and circumstances. The theory holds that, whereas a specific motivational state will be a more salient predictor of behavior in the immediate context, drive is a stronger predictor of future motivational states and associated outcomes. A hypothetical illustration of this relationship is presented in Figure 1. Theory and evidence suggest that drive is a multifaceted construct that plausibly manifests across life contexts (Siegling \& Petrides, 2016). It comprises interrelated processes, such as generating ideas, planning, initiating action, 
sustaining effort, and enjoyment of experiencing these processes. To appreciate its scope, it helps to examine the construct's measurement domain presented in this article.

Many agree that motivation is highest when people find themselves in contexts or roles maximally aligned with their talent, skills and personality. Drive theory is not at odds with this assumption. Rather, it holds that unsatisfied individuals, especially those high in drive, will strive to improve and make the best of their situation, capitalizing on the value of acquiring skills less aligned with their strengths or interests. When unaware of their talents and passions, people need to try themselves in different areas (even those they may be less interested or less likely to excel in initially) before pursuing a suitable career path. The driven individual is more likely to persist at seeking opportunities to the point at which they are in their element and able to draw heavily on their strengths.

Drive is distinguishable from constructs representing a person's motivational direction, or "motivators" (motives/needs, interests, etc.; e.g., Bernard, Mills, Swenson, \& Walsh, 2008; Reiss \& Havercamp, 1998; Schönbrodt \& Gerstenberg, 2012). Motivators represent the ulterior reasons for behavior (why a person engages in some behaviors, and not others), whereas drive describes the level of personal investment in the advancement of one's own, or others', condition and circumstances. Both Mother Teresa and a workaholic, highly successful CEO could be described as extremely driven, but may have entirely different agendas. A similar, more specific distinction is that between goal content and goal pursuit (Massey, Gebhardt, \& Garnefski, 2008), which implies that different people can have the same goal, yet differ in their propensity to act upon it, resulting in different success levels.

Of the three general motives/needs, drive may appear similar to need for achievement (also known as the achievement motive) and, indeed, the two constructs are expected to share some outcomes. People high in need for achievement may strive towards personal career success or, initially, good grades, because of rewarding experiences related to attainment 
(McClelland, 1985). Whilst success and mastery are associated outcomes of drive, with behavior even directed at specific goals, drive is about the advancement of self or others, more generally, as opposed to attainment per se. Driven individuals are less motivated by psychological or social rewards experienced as a function of attainment, which is what distinguishes the construct from need for achievement and other motives. That said, drive theory makes no assumption about specific motivational processes (e.g., intrinsic vs. extrinsic motivation), a question addressed by self-determination theory (Gagné et al., 2015; Ryan \& Deci, 2000). Beyond such processes, a host of attributes, such as having a growth mindset, high curiosity or a high need for cognition, may be implicated in drive.

Drive's theoretical underpinnings as well as the motivational content within common personality inventories imply some level of overlap with personality. Yet, drive is not only conceptually but also empirically distinguishable, as supported by evidence: Even when operationalized via items from personality inventories, drive facets emerged as a distinct factor in personality-factor space (Siegling \& Petrides, 2016). It would not be unreasonable to suggest that an interaction of biological, psychological and social factors explain individual differences in drive. For example, linkages to physiological energy levels, which are critical to good performance (Loehr \& Schwartz, 2005), are conceivable.

Interrelationships of motivation, personality and human physiology have been presumed for some time, as is apparent in Gray's (1970) theory of behavioral inhibition and activation.

\section{Measurement}

Measures of cognate constructs and of varying operational similarity to drive are summarized in Table 1 (measures of individual drive facets are omitted). Some of these tap into closely related, narrower attributes (grit, proactive personality, work engagement, amotivation), representing the broader drive construct partially. For example, the Grit Scale (Duckworth \& Quinn, 2009) comprises the subscales of passion and perseverance, which 
represent emotional and, partially, behavioral aspects of drive. Its narrower focus could be part of the reason that grit has attracted critique in its overlap with personality, especially conscientiousness (Credé, Tynan, \& Harms, 2017). As Table 1 indicates, other measures mingle drive-like facets with motivators, with some combining them into composite scores (Hogan \& Hogan, 1992; Liem \& Martin, 2012; Schuler, Thornton, Frintrup, \& MuellerHanson, 2004). For instance, Hogan's Personality Inventory (Hogan \& Hogan, 1992) includes an ambition scale, but only some of its six subscales seem to reflect drive.

In a deliberate effort to validate drive and develop a comprehensive measurement model, two preliminary measures were recently developed through a combination of theoretical and empirical steps (Siegling \& Petrides, 2016). At the theoretical stage, drive facets were systematically selected through qualitative steps from an extensive corpus of individual-difference attributes: the International Personality Item Pool (Goldberg et al., 2006). The selected facets were operationalized via multi-item ratings scales from the same item pool and, in the case of a short form, via single-item ratings scales. The former employed a Likert scale format, while the latter employed facet estimates. A statistical approach was then taken to refine the measurement domain and derive a preliminary structural model, using a mixture of exploratory and confirmatory factor analysis.

Hierarchically structured, the drive measurement model featured three layers: 13 facets at the base, three aspects as the mid-layer and the drive construct at the apex. The aspects represent emotional, behavioral and cognitive nuances of motivation. Similarly, Kahn's (1990) influential theory of work engagement features emotional, cognitive and physical aspects. Both measures evidenced various forms of validity and reliability, as well as uniqueness (e.g., drive's shared variance with ambition was 46.6\%). Yet, they were based on a pre-existing personality item pool and subject to measurement limitations, including 
variations in reliability and item numbers across subscales as well as a suboptimal response scale for the target construct.

\section{The Present Study}

Following promising initial findings, this study inaugurates the development and validation of an advanced drive inventory, grounded in contemporary scale construction principles and based on a construct-specific item pool. Evidence for theory and construct is accrued simultaneously. One aim was to minimize the level of social desirability and other common response problems in the scale items. Other advancements pursued included a response scale format that better reflects the essence of the construct as well as a sufficient and consistent number of items across facets. Following item development and selection, psychometric properties were examined: internal consistency and test-retest reliability, factor structure, convergent and discriminant validity, as well as predictive and incremental validity, using quasi outcomes. The short form (Drive Lite) served to cross-validate the results and support theoretical interpretations. In this fashion, it was also co-validated as an abbreviated measure for situations where multifaceted measurement is impractical, or the focus is on the global construct.

\section{Methods}

\section{Facets, Item Pool and Response Scale}

Some facet names were simplified or substituted with synonyms, while maintaining their core meaning. The reason was to align all facets closely with the ethos of the test and modernize the language. Revised facets along with their original versions in parentheses are: enjoyment (joyfulness), energy (liveliness), enthusiasm (zest/enthusiasm/vitality), optimism (hope/optimism), perseverance (industriousness/perseverance/persistence), pursuing goals (achievement striving) and courage (valor/bravery/courage). The full set of 13 facets is shown in Table 2. 
Items were framed as neutrally as possible to minimize socially desirable responding (Bäckström, Björklund, \& Larsson, 2009; Ziegler, 2014a). Double-barreled items, double negatives, colloquialisms/trendy expressions and leading or presumptive items (e.g., "I wish I was better at science") were avoided. Other parts of the instrument (type of response scale, number of response points, response scale labels) and scale development process (item and statistical analysis) were carefully considered as well, by following current and established scale-construction principles (Clark \& Watson, 1995; Furr, 2011; Johnson, Rosen, \& Chang, 2011; Woltz, Gardner, Kircher, \& Burrow-Sanchez, 2012; Worthington \& Whittaker, 2006; Ziegler, 2014b, 2015).

Twelve items, half of them reverse-scored, were written for each of the 13 facets over the course of two to three months, during which they were subjected to expert review. Reviewers were academics in psychometrics and professionals in the assessment industry. They made sure that the items make sense, represent their target facet and can be understood by adults. Modifications to the items were undertaken upon each review. The items are short self-descriptive statements and have a 6-point response scale, ranging from 1 (Almost Never or Never) to 6 (Almost Always or Always). A time-indefinite frequency scale was deemed to best reflect the essence of the construct (general motivational level). Intermediate scale points were not labelled, since they are not always interpreted as even psychological intervals (Woltz et al., 2012). Moreover, a neutral scale midpoint was avoided in view of evidence attesting to its limitations (Ziegler, 2015).

\section{Item Selection and Psychometric Properties}

Items were selected based on their statistical performance in two different samples to maximize the robustness of the results. The item pool of $12 \times 13$ facets was first administered to a mixed sample of students and workers, recruited from diverse sources. In this administration, loadings and item modalities, or distributions, were used to identify weak 
items. The reduced item set was then administered to a gender-balanced sample of workers, where seven items were selected to measure each facet. Final measurement models and internal reliabilities for the facet scales are presented for the worker sample, whereas testretest reliability was examined over a one-month period in a subgroup of the mixed sample $(N=46)$ for both forms. The factor structure was examined for both forms, using Exploratory Structural Equation Modelling (ESEM), which integrates the advantages of exploratory and confirmatory factor analysis (estimation of model fit, a priori specification of latent variable and indicator relations, rotation procedure, allowing cross-loadings among latent variables and indicators; Asparouhov \& Muthén, 2009). For example, it is possible to specify the indicators of a latent variable, which have freely estimated loadings, as well as the non-indicators of a latent variable to be set to be close to zero, without being fixed. The combined data of the two samples was used to satisfy the data requirements of ESEM.

Convergent/discriminant, predictive and incremental validity of the two measures were examined in the mixed sample. Due to construct and measurement overlap between drive and validation constructs, it was deemed essential to partial out personality variance in these analyses, with drive's uniqueness being of main interest. Convergent validity variables were grit and proactive personality. Discriminant validity variables were the motives of achievement, power, affiliation, intimacy and fear, as well as social desirability. Although the achievement motive has some similarity to drive and presumably some shared variance, it is conceptually distinguished as a motive and therefore included among the discriminant validity indices, along with other motives. Big Five personality traits also functioned as additional convergent and discriminant validity indicators: As discussed, drive theory implies a limited degree of shared variance with personality, whereas high correlations would suggest redundancy and call drive's value into question. The current academic performance of a subgroup of students $(N=194)$ was used to examine incremental validity, by controlling for 
Big Five personality and gender. Predictive validity variables measured at one-month follow-up were motivational states: mental energy, physical energy and social motivation $(N$ $=46)$.

This research was approved by the UCL Research Ethics Committee (Project ID Number: CEHP/2014/525).

Participants. A mixed sample $(N=307,80.0 \%$ female $)$ was recruited from online participant recruitment portals as well as a university subject pool with a large international student body. Most participants were based in the U.K. (52.8\%) or North America (36.5\%); the remainder were distributed across 23 other nations. The sample age range was 18.1 to 64.0 years, averaging 26.7 years $(S D=10.4)$. A sample portion was currently pursuing education (65.1\%), mostly at the university level (58.7\%). Many participants were currently working $(37.5 \%)$, and most had already completed secondary $(38.8 \%)$ or undergraduate university (34.9\%) education; some had completed advanced university degrees (14.0\%), while others held post-secondary (11.4\%) and even doctoral qualifications (1.3\%).

A worker sample from across the U.K. $(N=286,57.7 \%$ male $)$ was recruited through a commercial recruitment system and financially compensated for their time. The age range of this sample was 21.5 to 49.6 years with an average of 32.7 years $(S D=7.0)$, and participants had an average of 10.5 years of work experience $(S D=7.5)$. The most common occupational groups were professionals (35.3\%), technicians and associate professionals (15.7\%), managers (12.9\%), clerical support workers (12.2\%) and service and sales workers $(5.2 \%)$. Most participants had completed an undergraduate degree $(67.8 \%)$ or higher $(29 \%)$. A minority of the sample was enrolled in further education (4.5\%).

\section{Measures}

Mixed and worker samples. The mixed sample completed the full item pool (12 x 13 items) for the emerging Drive inventory, whereas the worker sample completed a reduced set 
omitting weak items. Following the item selection procedure, the final set of items selected was used for further analysis in both samples (i.e., the same items were used for all cases). Both samples also completed the Drive Lite, which uses single-item rating scales for the facets: respondents indicate how much each attribute describes them on a Likert scale, ranging from "not at all" (1) to "very much" (6). The Drive Lite can be used to measure the construct and its three aspects, but it is not suitable as a measure of the facets.

Mixed sample. Derived from the mixed sample, internal reliability coefficients for the psychometric instruments described in this subsection are included in Table 3. Validity evidence from the original studies is summarized below.

Big Five personality. The Big Five personality traits were measured using the International English Mini-Markers (Thompson, 2008), a psychometrically advanced version of Saucier's (1994) measure. Forty adjectives are responded to on a 1 (Inaccurate) to 5 (Accurate) Likert scale, indicating how accurately each characterizes the person. Factor analysis supported the five-factor structure and all five scores evidenced strong stability over a three-month period and moderate to strong convergence with an existing five-factor inventory.

Grit. The Short Grit Scale of 12 items provides a total score of the construct (Duckworth \& Quinn, 2009). Items are self-descriptive statements, rated on a 1 (Very much like me) to 5 (Not like me at all) Likert scale. A series of applications across age levels provided predictive validity evidence involving a range of criteria, including educational attainment, number of career changes, retention among military cadets, and performance in a national spelling bee. Grit scores also showed convergence for self- and observer ratings and test-retest reliability over a one-year period.

Proactive personality. A shortened 10-item version of the Proactive Personality Scale was used (Bateman \& Crant, 1993; Seibert, Crant, \& Kraimer, 1999). The scale items are 
self-descriptive statements based on a 7-point scale ( $1=$ "strongly disagree"; 7 = "strongly agree"). The scale demonstrated test-retest reliability over a three-month period and correlated with self-reported indicators of career success, such as salary, promotions and career satisfaction. These explanatory effects remained significant after controlling for a range of demographic and socioeconomic variables.

Drive estimate. Participants were asked to give a total estimate of their drive, by indicating how much the attribute describes them on a 6-point scale $(1=$ "not at all"; $6=$ "very much").

Motives. Explicit motives (achievement, power, affiliation, intimacy, fear) were measured using the Unified Motives Scales (Schönbrodt \& Gerstenberg, 2012). This psychometric instrument is based on an Item Response Theory analysis of other motive measures and has different forms of varying length. A 30-item version was used in this instance. Seventeen items are self-descriptive statements that have a "strongly disagree" (1) to "strongly agree" (6) response scale; 13 items represent goals and are rated on a "not important to me" (1) to "extremely important to me" (6) response scale. Psychometric analysis demonstrated the instrument's superior measurement precision and incremental validity over its underlying measures on various outcomes. Test-retest validity measured over a one-week period was high.

Social desirability. A refined version of the Social Desirability Scale-17 was used to measure this predominant response bias (Stöber, 2001). Due to corrected item-total correlations around zero, the refined version omits one of the original 17 true-false items asking respondents about their use of illegal drugs. The scale converged with other measures of social desirability and evidenced sensitivity to a desirability inducing scenario (fictitious job-application instructions). Discriminant validity evidence was presented in the form of 
(nonsignificant) correlations with Big Five personality scores, despite some overlap with agreeableness and conscientiousness.

Motivational states. The 27-item Motivation and Energy Inventory measures a person's current motivational states and has three interrelated subscales: Mental Energy, Social Motivation, and Physical Energy (Fehnel, Bann, Hogue, Kwong, \& Mahajan, 2004). Some items have a 6- or 7-point frequency scale, while others have a 5-point response scale. The items ask respondents about their feelings, behaviors and thoughts during the past four weeks. Factor analysis supported the three theoretical constructs, which also showed consistent negative correlations with depression scales and positive correlations with measures of work effectiveness and productivity. Further, each scale was responsive to treatment with antidepressants compared to a placebo.

Academic performance. Current academic performance was based on the standard U.K. classification system, which consists of nine performance levels: first-class honors (1st), 80+; first-class honors (1st), 75-79; first-class honors (1st), 70-74; second-class honors, upper division (2:1), 60-69; second-class honors, lower division (2:2), 50-59; third-class honors (3rd), 40-49; ordinary degree (pass), 30-39; fail, 20-29; fail, 0-19. Participants were asked to specify one of these levels, without giving an exact percentage.

Statistical analysis. Item analysis in the mixed sample entailed a series of principalaxis factor analyses as a gate-keeping procedure: one per facet involving the 12 original items. Items exhibiting weak loadings on the first factor were removed, but using a low cutoff $(<.20)$ to avoid a systematic elimination of items with low or high difficulties (Ziegler, 2014a). Skewed distributions are acceptable (in fact, needed to disperse item difficulties), whereas items with distinct multi-modal distributions were considered problematic and eliminated. The remaining items were administered to the worker sample, where the measurement model for each facet was tested and refined within a CFA framework. A 
mixture of modification indices, item difficulties (judged based on item means) and factor loadings was used for this purpose, although at this stage only items with non-significant loadings were eliminated initially. Otherwise, items were selected to minimize error covariances and optimize the spread and distribution of item means. Where these criteria did not support a unanimous selection decision, items with better face validity were retained.

ESEM including an oblique target rotation procedure was used to test the Drive and Drive Lite factor structure using MPlus, Version 8 (Muthén \& Muthén, 2017). Non-target loadings were set to be approximately zero (without being fixed), allowing deviations from zero specifications; primary loadings were freely estimated (Marsh, Morin, Parker, \& Kaur, 2014). ESEM solutions were then imported into a CFA framework, following the ESEMwithin-CFA procedure, which yields model fit estimates identical to those obtained via ESEM (Marsh, Nagengast, \& Morin, 2013). The purpose was to test a second-order model including a latent drive factor. CFA and ESEM solutions were estimated through robust maximum-likelihood estimation. Model fit indices used were: root mean square error of approximation (RMSEA) and its 90\% confidence interval (CI), comparative fit index (CFI), Tucker-Lewis index (TLI) and standardized root mean square residual (SRMR). The model fit criteria referenced were: $\mathrm{CFI}>.90$, TLI $>.90$, RMSEA $<.08$ and SRMR $<.10$ for acceptable fit; and CFI $>.95$, TLI $>.95$, RMSEA $<.05$, SRMR $<.08$ for excellent fit (Browne \& Cudeck, 1992; Marsh, Hau, \& Wen, 2004).

Zero-order correlations were computed in addition to partial correlations between drive and the specified validation constructs, with Big Five personality controlled. Logistic regression was used to examine the unique explanatory effects of drive scores on academic performance. Given uneven intervals between levels, academic performance was not treated as a continuous criterion variable. Instead, preliminary analysis of drive scores and numbers of student participants across performance levels led to the dichotomization into first- and 
second-class honors standing; with only three participants representing each of the lowest two performance levels (below second-class honors), these groups were omitted from the analysis. Figure 2 shows a noticeable gap between these two performance levels, compared to the differences within each. Control variables in this analysis were Big Five personality and gender.

\section{Results}

\section{Facet Measurement Models and Reliability}

Following item analysis in the mixed sample, the number of items per facet retained ranged from 7 to 10 . These were trialed in the worker sample, where the final set of $91(13 \mathrm{x}$ 7) was selected. Facet scale fit indices and internal reliabilities in the worker sample are shown in Table 2. All 13 facets demonstrated at least adequate internal consistency reliability, with most estimates exceeding an alpha value of .80 . On the other hand, facet scales showed a mixture of fit levels, with a few showing room for improvement.

Internal consistency (Cronbach's $\alpha$ ) for total drive scores was .97 in the worker sample and .96 in the mixed sample; for the Drive Lite it was .90 and .89 , respectively. Correlations between Drive and Drive Lite composite scores approximate a level suggesting congruence, but not too high to call the advantage of the 91-item composite into question (mixed sample $r=.81, p<.001$; worker sample $r=.83, p<.001$ ). One-month test-retest reliability in the mixed sample subgroup was moderate to strong (Drive $r=.64, p<.001$; Drive Lite $r=.70, p<.001)$.

\section{Factor Structure}

ESEM solutions for the combined sample, with rotation to the original three-factor structure, are shown in Table 4. Model fit was satisfactory, or close to satisfactory in case of two fit indices, for the Drive, $\chi^{2}(42)=383.01, p<.001, \mathrm{RMSEA}=.117(90 \% \mathrm{CI}=.107$ to $.128), \mathrm{CFI}=.928, \mathrm{TLI}=.866, \mathrm{SRMR}=.036$, and satisfactory-to-excellent for the Drive Lite, 
$\chi^{2}(42)=193.44, p<.001, \mathrm{RMSEA}=.078(90 \% \mathrm{CI}=.067$ to .089$), \mathrm{CFI}=.957, \mathrm{TLI}=.920$,

SRMR $=.030$. Irrespective of model fit, a three-factor model was recovered for both measures, which had the same internal structure. Concisely, they can be labelled "passion", "effort" and "ideation", respectively. Compared to the research version (Siegling \& Petrides, 2016), one facet (initiative) jumped from the behavioral factor (Effort) to the cognitive factor (Ideation), resulting in a more balanced structure of facets per aspect. As is normal, the correlated-factor and higher-order models were statistically indistinguishable; their fit indices were identical. Thus, neither of the two models emerges as being superior to the other.

\section{Convergent and Discriminant Validity}

Partial and zero-order correlations between drive and validation constructs are shown in Table 3. Correlation with the Big Five traits ranged from -.22 (Neuroticism, Drive Lite) to .49 (Conscientiousness, Drive), supporting the construct's ties to personality, but also highlighting its uniqueness. With personality held constant, Drive and Drive Lite scores had the highest correlations with convergent validity measures (grit, proactive personality, drive estimates) compared to discriminant validity measures (motives of power, affiliation, achievement, intimacy, fear; social desirability). The only exception was that Drive Lite scores correlated more strongly with the achievement motive than with grit. Despite the conceptual distinction made, a moderate partial correlation between drive and the achievement motive is not surprising, because of some shared behavioral manifestations and outcomes. Zero-order or partial correlations did not approach a level that would suggest equivalence, let alone redundancy. For example, the maximum shared variance is observed with proactive personality at $43.6 \%$ for Drive and $53.3 \%$ for Drive Lite. Nonsignificant partial correlations with social desirability indicate that any trace of socially desirable responding is not higher than would be expected for common personality measures.

\section{Predictive and Incremental Validity}


At one-month follow-up, predictive correlations with motivational states (mental energy, physical energy and social motivation) were moderate to strong in a subgroup of 46 participants, controlling for personality ( $r=.34$ to .70 ; see Table 3). Furthermore, both Drive and Drive Lite scores predicted university students' honors standing ( $1^{\text {st }}$ vs. $\left.2^{\text {nd }}\right)$ after controlling for gender and personality. Table 5 presents the logistic regression results. The chi-square goodness of fit test showed that the model distinguished between first- and second-class standing for both Drive, $\chi^{2}(7)=21.55, p<.01$, and Drive Lite scores, $\chi^{2}(7)=$ 17.46, $p=.01$. Likewise, the Hosmer-Lemeshow test indicated a good model fit to the data for both Drive, $\chi^{2}(8)=12.36, p=.14$, and Drive Lite scores, $\chi^{2}(8)=7.27, p=.51$. Indices of usefulness showed that the model explained between $10.5 \%$ (Cox \& Snell $R^{2}$ ) to $14.3 \%$ (Nagelkerke $R^{2}$ ) and between $8.6 \%\left(\right.$ Cox $\&$ Snell $R^{2}$ ) to $11.7 \%\left(\right.$ Nagelkerke $R^{2}$ ) of the variance in honors student standing, respectively. Conscientiousness was the only other significant predictor, but only for the Drive Lite.

\section{Discussion}

Although it is valuable to assess motivation in specific situations or time frames, drive is general and, thus, postulated to explain future engagement, performance and achievement outcomes in various life domains. The evidence presented here provides further support for theory and construct, which had not been explicitly defined and operationalized accordingly. The development of an advanced inventory and cross-validation via a short form were grounded in contemporary scale-construction methodology (Bäckström et al., 2009; Clark \& Watson, 1995; Furr, 2011; Johnson et al., 2011; Woltz et al., 2012; Worthington \& Whittaker, 2006; Ziegler, 2014a, 2014b, 2015) and analytical procedures, notably ESEM (Marsh et al., 2014). Consistency between the two forms and with previous results strengthens the findings and supports theoretical interpretations. 
The original facets (Siegling \& Petrides, 2016) were partially updated in language and operationalized via a new item pool. Items were selected via two samples based on item parameters, including difficulties, modalities and loadings. ESEM supported the original three-factor structure for both forms. Aside from one facet that jumped to a theoretically appropriate factor, the structure obtained for two preliminary versions was recovered.

Considering measurement differences and limitations of these prior versions, it makes sense to give greater weight to the present results. Results also support the instruments' reliability and convergent/discriminant, predictive and incremental validity. For instance, drive was a stronger predictor of academic performance than Big Five personality, notably conscientiousness, and the conceptual uniqueness of drive from need for achievement is substantiated. The two forms also evidenced adequate convergence, comparable correlations with validation constructs and re-test reliability over a one-month period.

\section{Applications}

In talent management, drive may facilitate personnel placement and promotion decisions. Who is not only competent but also motivated to climb the organizational ladder? In a high-potential assessment context, it can help differentiate between, and select from, high-ability candidates. Further, those considered for senior leadership positions will almost certainly need to show a certain level of motivation to deliver business results. Drive could help decide between people with similar credentials, potential and common goals, but differing in their propensity to pursue these relentlessly. Alternatively, it may help pre-screen (select-out from) large applicant pools where motivation is considered vital to performance, such as sales and customer service, trading or investment banking. Moreover, drive may have a place in assessing a person's level of fit with corporate culture and high-performance teams. Those used to a slow-pace environment may not fit into a fast-paced, results-driven line of business, and vice-versa. Similarly, it may facilitate the composition of high- 
performance teams and role (task) assignments within teams (who tends to go the extra mile?). HR professionals, I-O psychologists or even L\&D specialists can make connections between job demands and workers' drive profiles, which can serve as a vehicle for objective discourse and feedback.

At the individual career level, drive may facilitate professional orientation and goal setting, by showing whether career expectations align with the level of commitment required (e.g., is a leadership role or entrepreneurship appropriate?). A career guidance consultant can, for instance, determine the drive target profiles for a shortlist of career paths and compare these to the candidate's drive profile. Minor discrepancies might suggest areas where life adjustments may help the client succeed, in which case it is useful for them to know what makes up their drive. Larger discrepancies might suggest that a different career is better suited. As such, drive scores can act as a reality check for clients through objectivizing the demands of their career aspirations relative to their own level of drive.

Although drive is certainly not sufficient for any role, it may be considered generally beneficial (e.g., high drive could also compensate for a person's weaknesses) and routinely even as essential, as job descriptions frequently suggest. That said, it should be noted that higher drive is not necessarily always better; depending on context, a specific level of drive may be desirable over extreme drive, such as where low employee turnover is of interest. Some careers require adherence to routine practices (e.g., police officer or pilot) and provide limited opportunity for personal development and achievement. Excessive drive might impede performance in such roles. Relatedly, whilst the global drive score would appear to deliver key insights, the assessor may wish to zero in on drive facets specifically relevant to alternative applications and roles. 


\section{Limitations and Future Directions}

A widely recognized limitation of self-report is that of response biases. Care was taken in the generation of the item pool to minimize socially-mediated attraction to high or low ratings, by phrasing items as neutrally as possible. Results indicate that no unique level of social desirability is associated with drive scores. The extent to which various response biases influence drive scores and have real-world implications will be important to investigate. Insights will guide future applications and control procedures. More generally, investigation of other psychometric properties (e.g., age effects, measurement invariance and differential item functioning) to determine the generalizability and applicability of the inventory across contexts and groups is warranted.

Important concurrent and predictive validity evidence with real-world criteria is expected to accumulate. It will be essential to demonstrate the prediction of engagement, performance and achievement outcomes above job-related competencies and different conceptualizations of personality (e.g., DeYoung, 2014; McAdams, 1995). Even though drive explained academic achievement and predicted motivational states prospectively, this evidence is limited and does not disentangle construct and measurement effects. Moreover, it will be important to further test a critical implication of drive theory, which is that drive predicts whether someone will act on their motivators; it should differentiate between individuals with the same motives, goals or interests on relevant criteria. As well, the effects of drive's aspects and facets need investigation to showcase the potential uses of subscales to practitioners. In due course, options for scoring candidates (criterion-referenced, normreferenced) can be explored, allowing drive to fully awaken and demonstrate its value in research, and organizational and career assessment. 


\section{References}

Ariely, D. (2016). Payoff. New York, NY: Simon \& Schuster, Inc.

Asparouhov, T., \& Muthén, B. (2009). Exploratory Structural Equation Modeling. Structural Equation Modeling: A Multidisciplinary Journal, 16(3), 397-438. https://doi.org/10.1080/10705510903008204

Bäckström, M., Björklund, F., \& Larsson, M. R. (2009). Five-factor inventories have a major general factor related to social desirability which can be reduced by framing items neutrally. Journal of Research in Personality, 43(3), 335-344. https://doi.org/10.1016/j.jrp.2008.12.013

Bateman, T. S., \& Crant, J. M. (1993). The proactive component of organizational behavior: A measure and correlates. Journal of Organizational Behavior, 14(2), 103-118. https://doi.org/10.1002/job.4030140202

Bernard, L. C., Mills, M., Swenson, L., \& Walsh, R. P. (2008). Measuring motivation multidimensionally: Development of the Assessment of Individual MotivesQuestionnaire (AIM-Q). Assessment, 15(1), 16-35. https://doi.org/10.1177/1073191107306131

Browne, M. W., \& Cudeck, R. (1992). Alternative ways of assessing model fit. Sociological Methods \& Research, 21(2), 230-258. https://doi.org/10.1177/0049124192021002005

Chamorro-Premuzic, T., Adler, S., \& Kaiser, R. B. (2017). What science says about identifying high-potential employees. Harvard Business Review. Retrieved from https://hbr.org/2017/10/what-science-says-about-identifying-high-potentialemployees?utm_campaign=hbr\&utm_source=linkedin\&utm_medium=social\#comme nt-section

Clark, L. A., \& Watson, D. (1995). Constructing validity: Basic issues in objective scale development. Psychological Assessment, 7, 309-319. https://doi.org/10.1037/1040- 
3590.7.3.309

Credé, M., Tynan, M. C., \& Harms, P. D. (2017). Much ado about grit: A meta-analytic synthesis of the grit literature. Journal of Personality and Social Psychology, 113(3), 492-511. https://doi.org/10.1037/pspp0000102

DeYoung, C. G. (2014). Cybernetic Big Five Theory. Journal of Research in Personality, 56, 33-58. https://doi.org/10.1016/j.jrp.2014.07.004

Duckworth, A. L., Peterson, C., Matthews, M. D., \& Kelly, D. R. (2007). Grit: Perseverance and passion for long-term goals. Journal of Personality and Social Psychology, 92(6), 1087-101. https://doi.org/10.1037/0022-3514.92.6.1087

Duckworth, A. L., \& Quinn, P. D. (2009). Development and validation of the Short Grit Scale (Grit-S). Journal of Personality Assessment, 91(2), 166-74. https://doi.org/10.1080/00223890802634290

Fehnel, S. E., Bann, C. M., Hogue, S. L., Kwong, W. J., \& Mahajan, S. S. (2004). The development and psychometric evaluation of the Motivation and Energy Inventory (MEI). Quality of Life Research, 13(7), 1321-1336. https://doi.org/10.1023/B:QURE.0000037502.64077.4d

Furr, R. M. (2011). Response formats and item writing. In Scale construction and psychometrics for social and personality psychology (pp. 16-24). Los Angeles: SAGE Publications Ltd.

Gagné, M., Forest, J., Vansteenkiste, M., Crevier-Braud, L., van den Broeck, A., Aspeli, A. K., ... Westbye, C. (2015). The Multidimensional Work Motivation Scale: Validation evidence in seven languages and nine countries. European Journal of Work and Organizational Psychology, 24(2), 178-196. https://doi.org/10.1080/1359432X.2013.877892

Gallup. (2017). State of the American Workplace: 2008-2010. Gallup. Washington, DC. 
Retrieved from http://news.gallup.com/reports/199961/7.aspx

Goldberg, L. R., Johnson, J. A., Eber, H. W., Hogan, R., Ashton, M. C., Cloninger, C. R., \& Gough, H. G. (2006). The International Personality Item Pool and the future of public-domain personality measures. Journal of Research in Personality, 40, 84-96. https://doi.org/10.1016/j.jrp.2005.08.007

Gray, J. A. (1970). The psychophysiological basis of introversion-extraversion. Behaviour Research and Therapy, 8(3), 249-266. https://doi.org/10.1016/0005-7967(70)90069-0

Hogan, R., \& Hogan, J. (1992). Hogan Personality Inventory manual (2nd ed.). Tulsa, OK: Hogan Assessment Systems.

Johnson, R. E., Rosen, C. C., \& Chang, C.-H. (2011). To aggregate or not to aggregate: Steps for developing and validating higher-order multidimensional constructs. Journal of Business and Psychology, 26(3), 241-248. https://doi.org/10.1007/s10869-011-92381

Kahn, W. A. (1990). Psychological conditions of personal engagement and disengagement at work. Academy of Management Journal, 33(4), 692-724. https://doi.org/10.2307/256287

Kanfer, R., Frese, M., \& Johnson, R. E. (2017). Motivation related to work: A century of progress. Journal of Applied Psychology, 102(3), 338-355. https://doi.org/10.1037/ap10000133

Kaufman, S. B., \& Duckworth, A. L. (2017). World-class expertise: A developmental model. Wiley Interdisciplinary Reviews: Cognitive Science, 8(1-2). https://doi.org/10.1002/wcs.1365

Liem, G. A. D., \& Martin, A. J. (2012). The motivation and engagement scale: Theoretical framework, psychometric properties, and applied yields. Australian Psychologist, 47(1), 3-13. https://doi.org/10.1111/j.1742-9544.2011.00049.x 
Loehr, J., \& Schwartz, T. (2005). The power of full engagement. New York, NY: The Free Press.

Marsh, H. W., Hau, K. T., \& Wen, Z. (2004). In search of golden rules: Comment on hypothesis-testing approaches to setting cutoff values for fit indexes and dangers in overgeneralizing Hu and Bentler's (1999) findings. Structural Equation Modeling. https://doi.org/10.1207/s15328007sem1103_2

Marsh, H. W., Morin, A. J. S., Parker, P. D., \& Kaur, G. (2014). Exploratory Structural Equation Modeling: An integration of the best features of exploratory and confirmatory factor analysis. Annual Review of Clinical Psychology, 10(1), 85-110. https://doi.org/10.1146/annurev-clinpsy-032813-153700

Marsh, H. W., Nagengast, B., \& Morin, A. J. S. (2013). Measurement invariance of big-five factors over the life span: ESEM tests of gender, age, plasticity, maturity, and la dolce vita effects. Developmental Psychology, 49(6), 1194-1218. https://doi.org/10.1037/a0026913

Massey, E. K., Gebhardt, W. A., \& Garnefski, N. (2008). Adolescent goal content and pursuit: A review of the literature from the past 16 years. Developmental Review, 28(4), 421-460. https://doi.org/10.1016/j.dr.2008.03.002

Mayer, J. D., Faber, M. A., \& Xu, X. (2007). Seventy-five years of motivation measures (1930-2005): A descriptive analysis. Motivation and Emotion, 31(2), 83-103. https://doi.org/10.1007/s11031-007-9060-2

McAdams, D. P. (1995). What do we know when we know a person? Journal of Personality, 63(3), 365-396. https://doi.org/10.1111/j.1467-6494.1995.tb00500.x

McClelland, D. C. (1985). How motives, skills, and values determine what people do. American Psychologist, 40(7), 812-825. https://doi.org/10.1037/0003-066X.40.7.812 Muthén, L., \& Muthén, B. (2017). Mplus user's guide (8th ed.). Los Angeles: Author. 
https://doi.org/10.13155/29825

Pearson, T. (2015). The end of jobs: Money, meaning and freedom without the 9-5. Lioncrest Publishing.

Pink, D. H. (2009). Drive: The surprising truth about what motivates us. New York, NY: Riverhead Hardcover.

Reiss, S., \& Havercamp, S. M. (1998). Toward a comprehensive assessment of fundamental motivation: Factor structure of the Reiss Profiles. Psychological Assessment, 10(2), 97-106. https://doi.org/10.1037//1040-3590.10.2.97

Ryan, R. M., \& Deci, E. L. (2000). Self-determination theory and the facilitation of intrinsic motivation, social development, and well-being. The American Psychologist, 55(1), 68-78. https://doi.org/10.1037/0003-066X.55.1.68

Sackett, P. R., Lievens, F., Van Iddekinge, C. H., \& Kuncel, N. R. (2017). Individual differences and their measurement: A review of 100 years of research. Journal of Applied Psychology, 102(3), 254-273. https://doi.org/10.1037/ap10000151

Saucier, G. (1994). Mini-markers: A brief version of Goldberg's unipolar big-five markers. Journal of Personality Assessment, 63(3), 506-516. https://doi.org/http://dx.doi.org/10.1207/s15327752jpa6303_8

Schaufeli, W. B., Salanova, M., González-Romá, V., \& Bakker, A. B. (2002). The measurement of engagement and burnout: A two sample confirmatory factor analytic approach. Journal of Happiness Studies, 3, 71-92.

https://doi.org/10.1023/A:1015630930326

Schönbrodt, F. D., \& Gerstenberg, F. X. R. (2012). An IRT analysis of motive questionnaires: The Unified Motive Scales. Journal of Research in Personality, 46(6), 725-742. https://doi.org/10.1016/j.jrp.2012.08.010

Schuler, H., Thornton, G. C. I., Frintrup, A., \& Mueller-Hanson, R. (2004). Achievement 
Motivation Inventory (AMI). Oxford, UK: The Test Agency.

Schwartz, B. (2015). Why we work. TED/Simon \& Schuster.

Seibert, S., Crant, J., \& Kraimer, M. (1999). Proactive personality and career success. Journal of Applied Psychology, 84, 416-427.

Siegling, A. B., \& Petrides, K. V. (2017). Motivation (achievement, affiliation, power). In Wiley-Blackwell Encyclopedia of Personality and Individual Differences. Wiley.

Siegling, A. B., \& Petrides, K. V. (2016). Drive: Theory and construct validation. PLoS ONE, 11(7), e0157295. https://doi.org/10.1371/journal.pone.0157295

Sinek, S., Mead, D., \& Docker, P. (2017). Find your why. New York, NY: Portfolio/Penguin.

Stöber, J. (2001). The Social Desirability Scale-17 (SDS-17). European Journal of Psychological Assessment, 17(3), 222-232. https://doi.org/10.1027//10155759.17.3.222

Strack, R. (2014). Rainer Strack: The workforce crisis of 2030 - and how to start solving it now. Retrieved from https://www.ted.com/talks/rainer_strack_the_surprising_workforce_crisis_of_2030_a nd_how_to_start_solving_it_now/up-next

Thompson, E. R. (2008). Development and validation of an International English Big-Five Mini-Markers. Personality and Individual Differences, 45(6), 542-548. https://doi.org/10.1016/j.paid.2008.06.013

Vallerand, R. J., Pelletier, L. G., Blais, M. R., Briere, N. M., Senecal, C., \& Vallieres, E. F. (1992). The Academic Motivation Scale: A measure of intrinsic, extrinsic, and amotivation in education. Educational and Psychological Measurement, 52(4), 10031017. https://doi.org/10.1177/0013164492052004025

Woltz, D. J., Gardner, M. K., Kircher, J. C., \& Burrow-Sanchez, J. J. (2012). Relationship between perceived and actual frequency represented by common rating scale labels. 
Psychological Assessment, 24(4), 995-1007. https://doi.org/10.1037/a0028693

Worthington, R. L., \& Whittaker, T. A. (2006). Scale development research: A content analysis and recommendations for best practices. The Counseling Psychologist, 34(6), 806-838. https://doi.org/10.1177/0011000006288127

Ziegler, M. (2014a). Comments on item selection procedures. European Journal of Psychological Assessment, 30(1), 1-2. https://doi.org/10.1027/1015-5759/a000196

Ziegler, M. (2014b). Stop and state your intentions! Let's not forget the ABC of test construction. European Journal of Psychological Assessment, 30(4), 239-242. https://doi.org/10.1027/1015-5759/a000228

Ziegler, M. (2015). "F You, I won't do what you told me!" - Response biases as threats to psychological assessment. European Journal of Psychological Assessment, 31(3), 153-158. https://doi.org/10.1027/1015-5759/a000292 
Table 1

Measures of Cognate Constructs and of Varying Operational Similarity to Drive

\begin{tabular}{|c|c|c|}
\hline Measure & Main construct(s) & Subscales \\
\hline $\begin{array}{l}\text { Achievement Motivation Inventory } \\
\text { (Schuler et al., 2004) }\end{array}$ & self-control, ambition, self-assurance & 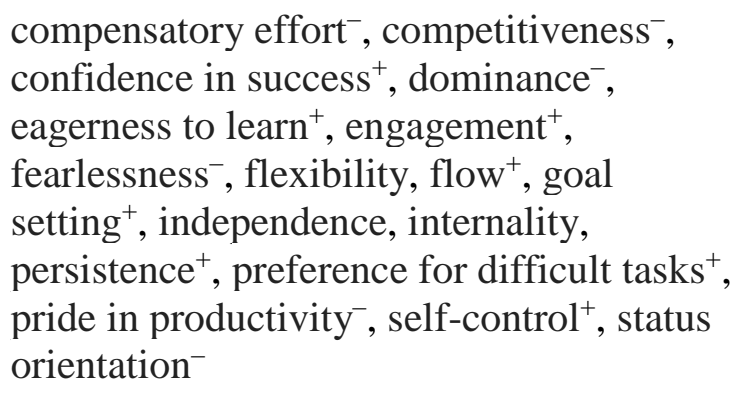 \\
\hline $\begin{array}{l}\text { Hogan Personality Inventory (Hogan \& } \\
\text { Hogan, 1992) }\end{array}$ & ambition & $\begin{array}{l}\text { competitive }^{-} \text {, self-confident } t^{+} \text {, no } \\
\text { depression, leadership, identity, no social } \\
\text { anxiety }^{-}\end{array}$ \\
\hline $\begin{array}{l}\text { Motivation and Engagement Scale (Liem } \\
\& \text { Martin, 2012) }\end{array}$ & $\begin{array}{l}\text { adaptive cognition, adaptive behavior, } \\
\text { impeding cognition, maladaptive behavior }\end{array}$ & $\begin{array}{l}\text { self-efficacy, valuing }{ }^{-}, \text {mastery orientation } \\
\text {, planning }^{+}, \text {task management }^{+} \text {, } \\
\text { persistence }^{+} \text {, anxiety } \\
\text { uncertain failure avoidance }{ }^{-}, \\
\text {disengagement }{ }^{+}\end{array}$ \\
\hline $\begin{array}{l}\text { Motivation and Energy Inventory (Fehnel } \\
\text { et al., 2004) }\end{array}$ & $\begin{array}{l}\text { mental energy, physical motivation, social } \\
\text { motivation }\end{array}$ & - \\
\hline Grit Scale (Duckworth, Peterson, & grit & passion $^{+}$, perseverance $^{+}$ \\
\hline
\end{tabular}

Matthews, \& Kelly, 2007) 
Utrecht Work Engagement Scale

(Schaufeli, Salanova, González-Romá, \&

Bakker, 2002)

Proactive Personality Scale (Bateman \&

Crant, 1993)

Multidimensional Work Motivation Scale

(Gagné et al., 2015), Academic Motivation

Scale (Vallerand et al., 1992)

Note. Subscales reflective of drive are denoted by plus (+) signs; subscales reflective of motivators (motives/needs, goals, values, etc.) are denoted by minus (-) signs. vigor $^{+}$, dedication $^{+}$, absorption $^{+}$

proactive personality

amotivation 
Table 2

Facet Scale Fit Indices and Internal Reliabilities in the Worker Sample

\begin{tabular}{|c|c|c|c|c|c|c|c|}
\hline Facet & $\chi^{2}(14)$ & CFI & TLI & RMSEA & $\begin{array}{c}\text { RMSEA } \\
90 \% \text { CI }\end{array}$ & SRMR & $\begin{array}{c}\text { Cronbach's } \\
\alpha\end{array}$ \\
\hline Enjoyment & $113.57 * * *$ & .905 & .858 & .158 & {$[.132, .186]$} & .064 & .87 \\
\hline Energy & $145.00 * * *$ & .878 & .816 & .181 & {$[.155, .208]$} & .083 & .88 \\
\hline Enthusiasm & 20.97 & .992 & .988 & .042 & {$[.000, .077]$} & .026 & .87 \\
\hline Optimism & $65.41 * * *$ & .914 & .871 & .144 & {$[.087, .142]$} & .059 & .82 \\
\hline Self-confidence & $47.61 * * *$ & .961 & .941 & .092 & {$[.064, .121]$} & .042 & .84 \\
\hline Diligence & $38.61 * * *$ & .969 & .954 & .079 & {$[.050, .109]$} & .038 & .75 \\
\hline Self-discipline & $107.36 * * *$ & .830 & .745 & .153 & {$[.127, .181]$} & .091 & .79 \\
\hline Pursuing goals & 21.36 & .992 & .988 & .043 & {$[.000, .077]$} & .025 & .85 \\
\hline Perseverance & $74.37 * * *$ & .943 & .915 & .123 & {$[.096, .151]$} & .051 & .82 \\
\hline Insightfulness & $205.97 * * *$ & .614 & .421 & .219 & {$[.193, .246]$} & .127 & .79 \\
\hline Generating ideas & 23.12 & .989 & .983 & .048 & {$[.000, .081]$} & .027 & .83 \\
\hline Initiative & 21.14 & .987 & .981 & .042 & {$[.000, .077]$} & .033 & .78 \\
\hline Courage & $27.61 *$ & .980 & .970 & .058 & {$[.025, .090]$} & .035 & .77 \\
\hline
\end{tabular}

Note. $N=286 . \mathrm{CFI}=$ comparative fit index; $\mathrm{TLI}=$ Tucker-Lewis index; $\mathrm{RMSEA}=$ root mean square error of approximation; $\mathrm{CI}=$ confidence interval; $\mathrm{SRMR}=$ standardized root mean square residual.

$* p<.05 . * * p<.01 . * * * p<.001$. 
Table 3

Construct Validity in the Mixed Sample

Drive $(N=307) \quad$ Drive Lite $(N=306)$

Validation construct

$\begin{array}{lll}\text { Partial } r & r & \text { Partial } r\end{array}$

$r$

Big Five personality

Neuroticism (.81)

$\begin{array}{cccc}- & -.35^{* * * *} & - & -.22 * * * \\ - & .41^{* * *} & - & .42 * * * \\ - & .32^{* * *} & - & .42 * * * \\ - & .37 * * * & - & .46 * * * \\ - & .49 * * * & - & .44 * * *\end{array}$

Conscientiousness (.81)

Convergent validity

Grit (.80)

$\begin{array}{llll}.49 * * * & .56 * * * & .21 * * * & .45 * * * \\ .45^{* * *} & .66^{* * *} & .54 * * * & .73 * * * \\ .49 * * * & .66 * * * & .64 * * * & .75 * * *\end{array}$

Drive estimate $(N=300)$

$.49 * *$

$.66 * * *$

$.64 * * *$

$.75^{* * *}$

Discriminant validity

Achievement motive (.88)

$.35 * * *$

$.53 * * *$

$.43 * * *$

$.62 * * *$

Power motive (.84)

.05

$.21 * * *$

$.19 * *$

$.30 * * *$

Affiliation motive (.81)

.03

$.30 * * *$

$.17 * *$

$.39 * * *$

Intimacy motive (.85)

.09

$.24 * * *$

$.25 * * *$

$.41 * * *$

Fear (.81)

$-.24 * * *$

$-.34 * * *$

$-.00$

$-.13^{*}$

Social desirability (.69)

.01

$.19 * * *$

.01

$.17 * *$

Predictive validity ( 1 month; $N=46$ )

Mental energy (.88)

$.66 * * *$

$.55 * * *$

$.70 * * *$

$.49 * * *$

Social motivation (.78)

$.34 *$

$.34 *$

$.54 * * *$

$.45 * *$

Physical motivation (.85)

$.49 * *$

$.37 *$

$.66^{* * *}$

$.43 * *$ 
Note. Partial correlations include Big Five personality as control variables. Cronbach's alphas for validation constructs are shown in parentheses.

${ }^{*} p<.05 . * * p<.01 . * * * p<.001$. 
Table 4

ESEM Factor Loadings for Drive and Drive Lite Scores, Factor Covariance Matrix and Higher-Order Loadings in the Mixed and Worker Samples (Combined)

Drive $(N=593)$

Drive Lite $(N=591)$

Variable Passion Effort Ideation Residual Passion Effort Ideation Residual

First-order factor loadings

\begin{tabular}{lcccccccc} 
Enjoyment & $\mathbf{1 . 0 6}$ & -0.15 & -0.14 & 0.11 & $\mathbf{0 . 9 3}$ & -0.11 & -0.06 & 0.30 \\
Enthusiasm & $\mathbf{0 . 8 9}$ & 0.06 & -0.16 & 0.25 & $\mathbf{0 . 7 8}$ & 0.00 & 0.10 & 0.29 \\
Energy & $\mathbf{0 . 6 6}$ & 0.06 & -0.08 & 0.57 & $\mathbf{0 . 7 3}$ & 0.13 & -0.16 & 0.48 \\
Optimism & $\mathbf{0 . 5 1}$ & 0.06 & 0.35 & 0.40 & $\mathbf{0 . 7 5}$ & -0.06 & 0.07 & 0.44 \\
Self-confidence & $\mathbf{0 . 4 4}$ & 0.09 & 0.41 & 0.40 & $\mathbf{0 . 4 9}$ & 0.12 & 0.11 & 0.59 \\
Self-discipline & -0.03 & $\mathbf{0 . 8 8}$ & -0.11 & 0.34 & 0.00 & $\mathbf{0 . 8 9}$ & -0.22 & 0.38 \\
Diligence & -0.01 & $\mathbf{0 . 8 3}$ & -0.06 & 0.37 & -0.04 & $\mathbf{0 . 7 0}$ & 0.08 & 0.48 \\
Perseverance & 0.11 & $\mathbf{0 . 7 0}$ & 0.04 & 0.39 & 0.01 & $\mathbf{0 . 6 6}$ & 0.14 & 0.43 \\
Pursuing goals & 0.04 & $\mathbf{0 . 6 3}$ & 0.25 & 0.33 & 0.13 & $\mathbf{0 . 5 7}$ & 0.21 & 0.37 \\
Generating ideas & 0.06 & -0.19 & $\mathbf{0 . 7 9}$ & 0.47 & 0.04 & -0.12 & $\mathbf{0 . 7 6}$ & 0.48 \\
Insightfulness & -0.11 & 0.06 & $\mathbf{0 . 6 4}$ & 0.61 & -0.02 & 0.02 & $\mathbf{0 . 6 5}$ & 0.59 \\
Courage & 0.10 & 0.31 & $\mathbf{0 . 5 9}$ & 0.26 & 0.17 & 0.17 & $\mathbf{0 . 3 9}$ & 0.60 \\
Initiative & 0.21 & 0.15 & $\mathbf{0 . 5 9}$ & 0.35 & 0.00 & 0.20 & $\mathbf{0 . 5 8}$ & 0.49 \\
\hline
\end{tabular}

Factor covariances (correlated-factors model)

Passion

\begin{tabular}{lllllll} 
Effort & 0.53 & - & & 0.60 & - & \\
Ideation & 0.44 & 0.53 & - & 0.61 & 0.56 & - \\
\hline
\end{tabular}

Second-order factor loadings (higher-order model) 
Drive

$0.77 \quad 0.89$

0.79

0.8

0.74

0.76

Note. All estimates are standardized, and target loadings are shown in bold. All factor covariances and second-order loadings are significant at the $<.001$ level. ESEM $=$ Exploratory Structural Equation Modelling. 
Table 5

Logistic Regression Analysis Predicting Students' Honors Standing with Gender, Big Five Personality and Drive in Undergraduate Students

\begin{tabular}{|c|c|c|c|c|c|c|}
\hline Variables & $B$ & $S E$ & $O R$ & $95 \% \mathrm{CI}$ & $\begin{array}{c}\text { Wald } \\
\text { statistic }\end{array}$ & $p$ \\
\hline \multicolumn{7}{|c|}{ Drive } \\
\hline Gender & -0.45 & 0.48 & 0.64 & {$[0.25,1.62]$} & 0.89 & 0.346 \\
\hline Neuroticism & -0.23 & 0.24 & 0.80 & {$[0.50,1.26]$} & 0.94 & 0.332 \\
\hline Extraversion & 0.32 & 0.20 & 1.38 & {$[0.93,2.04]$} & 2.57 & 0.109 \\
\hline Openness & -0.14 & 0.28 & 0.87 & {$[0.50,1.49]$} & 0.27 & 0.603 \\
\hline Agreeableness & 0.19 & 0.30 & 1.21 & {$[0.67,2.20]$} & 0.40 & 0.529 \\
\hline Conscientiousness & -0.36 & 0.24 & 0.70 & {$[0.44,1.12]$} & 2.19 & 0.139 \\
\hline Drive & -1.25 & 0.42 & 0.29 & {$[0.13,0.65]$} & 8.84 & 0.003 \\
\hline \multicolumn{7}{|c|}{ Drive Lite } \\
\hline Gender & -0.57 & 0.47 & 0.56 & {$[0.22,1.42]$} & 1.48 & 0.224 \\
\hline Neuroticism & -0.11 & 0.23 & 0.90 & {$[0.58,1.40]$} & 0.22 & 0.640 \\
\hline Extraversion & 0.29 & 0.20 & 1.34 & {$[0.90,1.99]$} & 2.08 & 0.149 \\
\hline Openness & -0.17 & 0.28 & 0.84 & {$[0.49,1.45]$} & 0.37 & 0.541 \\
\hline Agreeableness & 0.12 & 0.30 & 1.12 & {$[0.63,2.02]$} & 0.15 & 0.695 \\
\hline Conscientiousness & -0.46 & 0.23 & 0.63 & {$[0.40,0.99]$} & 4.00 & 0.046 \\
\hline Drive & -0.66 & 0.29 & 0.52 & {$[0.29,0.91]$} & 5.16 & 0.023 \\
\hline
\end{tabular}

Note. $N=194.1^{\text {st }}$-class was coded $1(n=74) ; 2^{\text {nd }}$-class was coded $2(n=120)$. Male students were coded $1(n=26)$; female students were coded $2(n=168)$. CI $=$ confidence interval for odds ratio $(O R)$. 


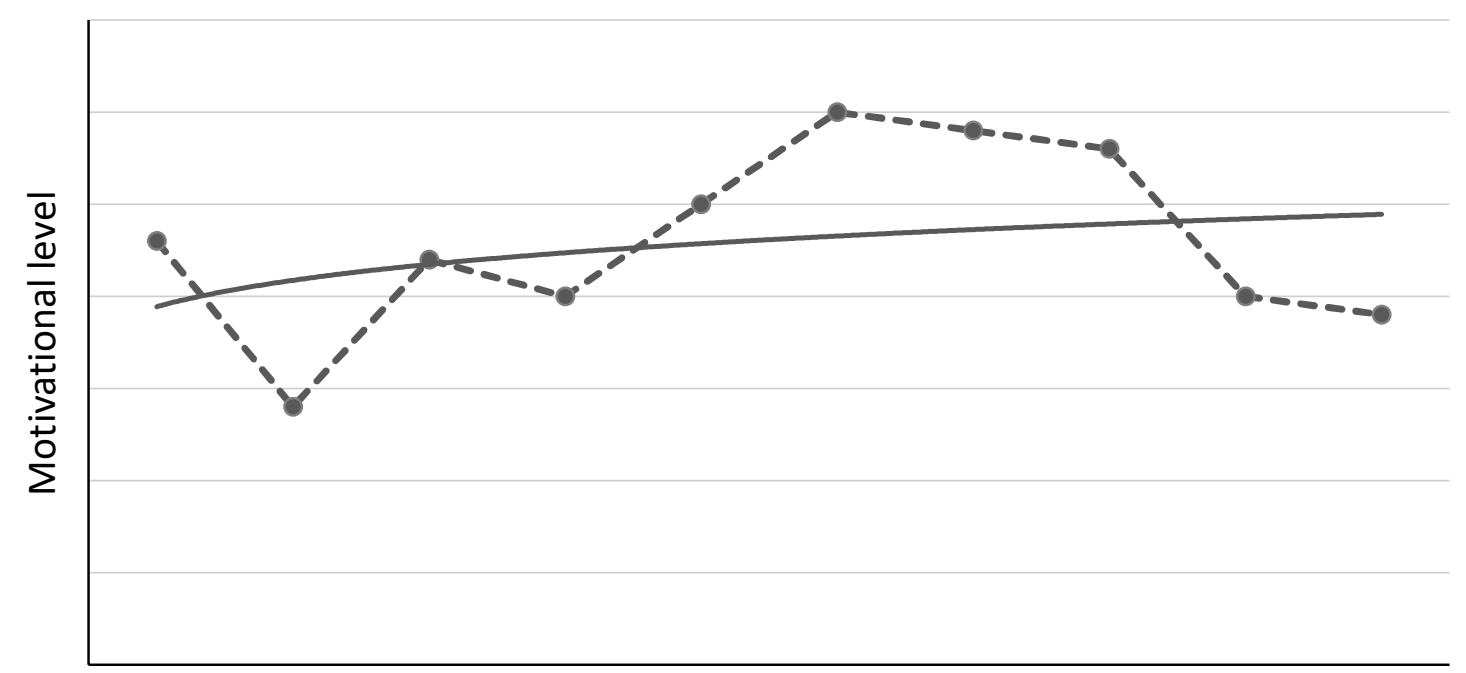

Time 1 Time 2 Time 3 Time 4 Time 5 Time 6 Time 7 Time 8 Time 9 Time 10 - - Motivational state - Drive

Figure 1. Hypothetical illustration of the relationship between drive and motivational states. 


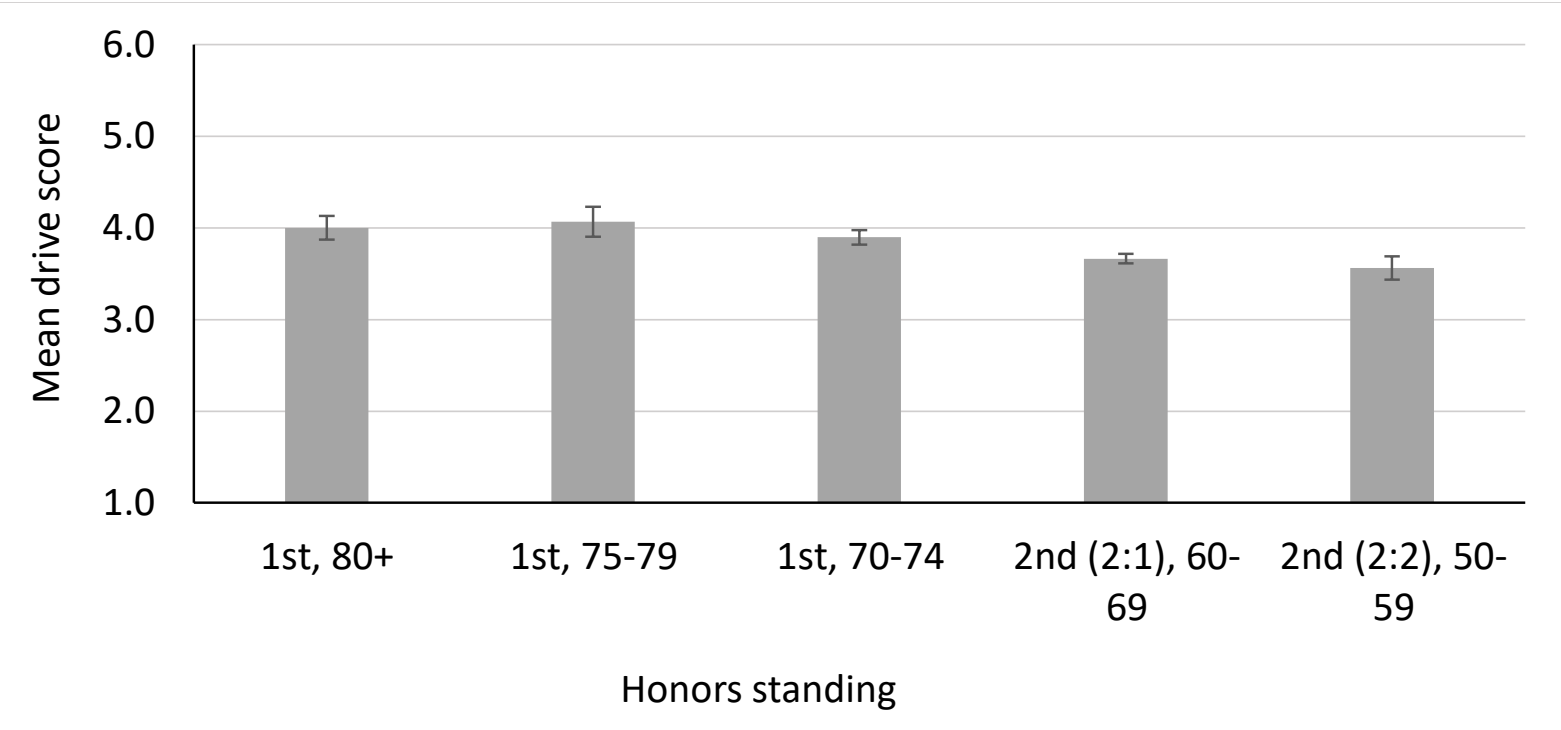

Figure 2. Mean drive scores and current academic performance in undergraduate students $(N$ = 194). 